\title{
Article \\ Elucidating the Influence of the d-Band Center on the Synthesis of Isobutanol
}

\author{
Johannes Häusler 1,*(D), Joachim Pasel ${ }^{1, *}$, Friederike Woltmann ${ }^{1}$, Andreas Everwand ${ }^{1}$, Maria Meledina ${ }^{2,3}$, \\ Helen Valencia ${ }^{2,3}$, Marta Lipińska-Chwałek ${ }^{2,3}{ }^{(D}$, Joachim Mayer ${ }^{2,3}$ and Ralf Peters ${ }^{1}$ (D)
}

1 IEK-14: Electrochemical Process Engineering, Institute of Energy and Climate Research, Forschungszentrum Jülich $\mathrm{GmbH}$, 52425 Jülich, Germany; f.woltmann@fz-juelich.de (F.W.); a.everwand@fz-juelich.de (A.E.); ra.peters@fz-juelich.de (R.P.)

2 Central Facility for Electron Microscopy (GFE), RWTH Aachen University, 52074 Aachen, Germany; meledina@gfe.rwth-aachen.de (M.M.); valencia@gfe.rwth-aachen.de (H.V.); m.lipinska@fz-juelich.de (M.L.-C.); mayer@gfe.rwth-aachen.de (J.M.)

3 Ernst Ruska-Centre (ER-C) for Microscopy and Spectroscopy with Electrons, Forschungszentrum Jülich $\mathrm{GmbH}, 52425$ Jülich, Germany

* Correspondence: j.haeusler@fz-juelich.de (J.H.); j.pasel@fz-juelich.de (J.P.); Tel.: +49-2461-61-5393 (J.H.)

\section{check for}

updates

Citation: Häusler, J.; Pasel, J.;

Woltmann, F.; Everwand, A.

Meledina, M.; Valencia, H.;

Lipińska-Chwałek, M.; Mayer, J.;

Peters, R. Elucidating the Influence of the d-Band Center on the Synthesis of Isobutanol. Catalysts 2021, 11, 406. https://doi.org/10.3390/catal11030406

Academic Editors: Albin Pintar,

Nataša Novak Tušar and

Günther Rupprechter

Received: 1 March 2021

Accepted: 19 March 2021

Published: 23 March 2021

Publisher's Note: MDPI stays neutral with regard to jurisdictional claims in published maps and institutional affiliations.

Copyright: (c) 2021 by the authors. Licensee MDPI, Basel, Switzerland. This article is an open access article distributed under the terms and conditions of the Creative Commons Attribution (CC BY) license (https:/ creativecommons.org/licenses/by/ $4.0 /)$

\begin{abstract}
As the search for carbon-efficient synthesis pathways for green alternatives to fossil fuels continues, an expanding class of catalysts have been developed for the upgrading of lower alcohols. Understanding of the acid base functionalities has greatly influenced the search for new materials, but the influence of the metal used in catalysts cannot be explained in a broader sense. We address this herein and correlate our findings with the most fundamental understanding of chemistry to date by applying it to d-band theory as part of an experimental investigation. The commercial catalysts of $\mathrm{Pt}, \mathrm{Rh}, \mathrm{Ru}, \mathrm{Cu}, \mathrm{Pd}$, and Ir on carbon as a support have been characterized by means of SEM, EDX-mapping, STEM, XRD, $\mathrm{N}_{2}$-physisorption, and $\mathrm{H}_{2}$-chemisorption. Their catalytic activity has been established by means of c-methylation of ethanol with methanol. For all catalysts, the TOF with respect to i-butanol was examined. The $\mathrm{Pt} / \mathrm{C}$ reached the highest $\mathrm{TOF}$ with a selectivity towards i-butanol of $89 \%$. The trend for the TOFs could be well correlated with the d-band centers of the metal, which formed a volcano curve. Therefore, this study is another step towards the rationalization of catalyst design for the upgrading of alcohols into carbon-neutral fuels or chemical feedstock.
\end{abstract}

Keywords: Guerbet reaction; volcano curve; d-band center; hydrogen borrowing; carbon neutral fuel; i-butanol; heterogeneous catalysis

\section{Introduction}

In order to reduce the chemical industry's carbon footprint, extensive research is being conducted into the use of abundant renewable resources for higher value products. It is apparent that products with short lifecycles, in particular, will have a small carbon footprint, as their throughput is typically very large. Producing such products in a carbon-neutral manner could greatly reduce carbon dioxide emissions. This is especially the case for fuels.

One common possibility for the efficient atom synthesis of higher molecules is the C-C formation by means of homo aldol condensation combined with a hydrogen borrowing approach, which is known in the literature as the Guerbet reaction [1]. Further, 1-butanol has been frequently discussed as a drop-in fuel to reduce the carbon footprint of fossil fuels. Various approaches have been undertaken to synthesize more effective catalysts, and have been reviewed in several works [2-4]. Special attention is paid to tuning the base/acidity relationships of the support. The acid base bifunctionality is known to play a key role in the selectivity of the catalyst [5-8]. In the work of Quesada et al., Cu supported on the $\mathrm{Mg}$-Al-oxide reduced the amount and density of acidic sites. Most prominently, strong acidic sites were reduced by $93 \%$ down to only $3.1 \mu \mathrm{mol} / \mathrm{g}$. At the same time, the strong 
basic sites were reduced by $73 \%$ down to $62.5 \mu \mathrm{mol} / \mathrm{g}$. Although the conversion of ethanol increased, the selectivity to the dehydration products of ethene and 1,3-butadiene were reduced within the $\mathrm{Cu} / \mathrm{Mg}-\mathrm{Al}$ catalyst, thus clearly indicating the significant influence of the strong acid/base sites for the dehydration mechanisms to olefins [8]. On the other hand, Cimino et al. found that $\mathrm{Ni}$ supported by $\mathrm{MgO}$ increased the number of basic sites [6]. Zhang et al. used a $\mathrm{Mg}_{x} \mathrm{Al}-\mathrm{LDO}$ (layered double hydroxide) with ratios of $\mathrm{Mg}$ to $\mathrm{Al}$ ranging from 1 to 4 loaded with $8 \mathrm{~nm}$ Ag-particles, in which the density of the basic sites was much higher compared to the $\mathrm{Cu} / \mathrm{MgAl}$ catalyst described above. With an acid base site ratio of 0.41 , the conversion and selectivity towards n-butanol was optimal in the case of this support [9]. Other supports, such as hydroxyapatite, were also used and the ratios of $\mathrm{Ca} / \mathrm{P}$ and $\mathrm{Sr} / \mathrm{P}$ were investigated in order to identify an optimal acid base site ratio $[10,11]$. We fundamentally agree with Cimino et al. that the addition of metals to a surface alters its functionalities depending on the metal and the surface on which it is supported. Therefore, it is difficult to distinguish between the effects of the metal's addition and the alteration of surface functionalities solely by reference to conversion and selectivity. In order to determine the influence of the metal used, experiments were performed with various transition metals, although the support remained the same.

Riittonnen et al. screened several Al-oxide-supported metals, namely, $\mathrm{Ni}, \mathrm{Pt}, \mathrm{Au}$, $\mathrm{Rh}, \mathrm{Ru}$, and Ag using both self-prepared and commercial catalysts. They achieved the highest conversion using $\mathrm{Ni} / \mathrm{Al}_{2} \mathrm{O}_{3}$ with a $25 \%$ ethanol conversion and selectivity of $80 \%$ towards 1-butanol at $250{ }^{\circ} \mathrm{C}$. The catalyst-to-ethanol ratio was relatively high, with a loading of $4 \%$ (mass catalyst/mass ethanol and catalyst). However, detailed information about surface acid-base pairs was not derived [12]. A similar study was performed by Marcu et al., who investigated the activity of different metals on $\mathrm{Mg}-\mathrm{Al}$-oxides, each of which was loaded with $5 \% \mathrm{Pd}, \mathrm{Ag}, \mathrm{Mn}, \mathrm{Fe}, \mathrm{Cu}, \mathrm{Sm}$, and $\mathrm{Yb}$. Here, the Pd5MgAlO catalyst was the most selective towards 1-butanol (73\%) after $5 \mathrm{~h}$ of reaction time at $200{ }^{\circ} \mathrm{C}$ and a conversion of $3.8 \%$ ethanol. This was followed by the $\mathrm{Cu} 5 \mathrm{MgAlO}$ catalyst, which exhibited a higher conversion, which accompanied a high selectivity towards acetalization. Marcu et al. determined that the influence of the metal itself was only secondary in nature, as the catalyst conversions and selectivity correlated strongly with the established number of strong base sites, which was the highest for the Pd5MgAlO catalyst. Although the $\mathrm{Cu} 5 \mathrm{MgAlO}$ exhibited a similar number of strong base sites, the selectivity was $40 \%$ with respect to acetal formation [13]. Another study with a series of transition metals was performed with activated carbon as the support and $\mathrm{CeO}_{2}$ as the base. The hydrogen treatment of the catalysts increased the basicity of the $\mathrm{CeO}_{2}$. The highest conversion was found for the $\mathrm{Cu}-\mathrm{CeO}_{2} / \mathrm{AC}$ catalyst, at $46 \%$, and a selectivity towards n-butanol of $41 \%$. Selectivities of $20 \%$ for C6 compounds and $11 \%$ for ethyl acetate were found with the same catalyst. The highest selectivity was achieved with a Pd-CeO/AC catalyst, with $68 \%$ for nbutanol and only $6 \%$ towards $\mathrm{C} 6+$ products and $5 \%$ towards ethyl acetate. The conversions were 3.4 times lower compared to the $\mathrm{Cu}-\mathrm{CeO}_{2} / \mathrm{AC}$ catalyst. A direct correlation with the basic centers was not determined by Wu et al., but they stated that metals with a tendency for hydrogen spillover reduced the $\mathrm{CeO}_{2}$ more easily and thereby increased the basicity and selectivity with respect to $n$-butanol synthesis [14]. Comparisons of the amount of adsorbed $\mathrm{CO}_{2}$ also displayed good correlations with the selectivity.

Later, $\mathrm{Wu}$ et al. suggested that the experiments by Riittonnen et al. could be correlated with the d-band center of the metals on the alumina surface, as a decrease in the conversion was accompanied by a decrease in the d-band center values of the metals tested [3]. As the acid-base pairs were not determined in Riittonnen et al.'s study and the influence of the acid base sites on the reaction was not taken into account, this dependency was not robust.

Since Hammer and Nørskov published the d-band model, several studies have confirmed the dependency of the d-band center and the activity in chemical reactions [15-19]. The d-band model shows, that the center of gravity of the d-band (d-band center) in relation to the Fermi-Level of the metals or alloys, is connected to the strength of the transition metal-adsorbate interaction in a Sabatier type correlation, forming a volcano plot. As the 
distance between the d-band center and the Fermi level is increased, the energy of the resulting antibonding orbitals, which are formed by interaction by the orbital splitting with a surface adsorbate, also decreases. Consequently, an increasing proportion of antibonding states weakens the metal-adsorbate bond and facilitates desorption. In the case of a higher d-band center, however, desorption will be reduced due to the proportion of unoccupied states above the Fermi level and a consequently stronger metal-adsorbate interaction $[18,19]$.

The reactions used in those studies are mostly limited to small molecules, like $\mathrm{CO}, \mathrm{H}_{2}$, $\mathrm{N}_{2}$, and $\mathrm{C}_{2} \mathrm{H}_{2}$ as probe molecules [20-23]. To the best of our knowledge, no attempt has been made to test this dependency in a complex multistep reaction. Therefore, the aim of this study is to test whether the d-band of the transition metals is a reasonable descriptor for the activity in the synthesis of higher alcohols. In order to rule out the influence of acid base pairs, we adapted the protocol of Siddiki et al., who used methanol as a methylation agent for several aromatic and aliphatic ketones, as well as alcohols with high degrees of selectivity and conversion. Sodium hydroxide was used in large quantities, thereby ruling out the influence of surface acid-base pairs on the condensation process [24]. In order to avoid selectivity problems with the subsequent condensation of products, we selected ethanol to be methylated twice into i-butanol. I-butanol is a versatile base chemical and has also been tested as a carbon-neutral fuel [25]. Thanks to its higher octane numbers, lower soot production, and higher compressibility in internal combustion engines, it has emerged as a superior fuel over n-butanol [26-28].

\section{Results}

\subsection{Catalyst Characterization}

The catalysts were analyzed by means of nitrogen physisorption using the BET method for the surface calculations [29]. The catalysts possess very similar type IV isotherms, with a very large surface area attributable to micro-pores. As can be seen in Table $1, \mathrm{Cu} / \mathrm{C}$ had the largest specific surface area. The specific surface areas of the catalysts $\mathrm{Ir} / \mathrm{C}, \mathrm{Pt} / \mathrm{C}$, and $\mathrm{Rh} / \mathrm{C}$ were each in the range of $800-1000 \mathrm{~m}^{2} / \mathrm{g}$. The lowest specific surface area was measured for $\mathrm{Ru} / \mathrm{C}$, which totaled $6.6 \mathrm{~m}^{2} / \mathrm{g}$ and with a pore volume of $0.01 \mathrm{~mL} / \mathrm{g}$. The hysteresis of all catalysts was type-H4, which was closed at $\mathrm{p} / \mathrm{p} 0=0.95$. This points towards a complex pore structure [30]. The mean pore radii as determined by the $\mathrm{BJH}$ method was in the range of $18 \pm 1 \AA$ for all catalysts, whereas the pore volumes of the catalysts differed in the same manner as the specific BET area. Therefore, $\mathrm{Cu} / \mathrm{C}$ possessed the largest pore volume and $\mathrm{Ru} / \mathrm{C}$ had an extremely low pore volume of $0.01 \mathrm{~mL} / \mathrm{g}$.

Table 1. Results of the physisorption experiments.

\begin{tabular}{cccc}
\hline Catalyst & BET & Total Pore Volume & Pore Radius \\
\hline & $\mathbf{m}^{\mathbf{2}} \mathbf{g}$ & $\mathbf{m L} / \mathbf{g}$ & $\AA$ \\
\hline $5 \% \mathrm{Pd} / \mathrm{C}$ & 980.06 & 0.68 & 18.13 \\
$5 \% \mathrm{Pt} / \mathrm{C}$ & 805.10 & 0.59 & 16.99 \\
$5 \% \mathrm{Ru} / \mathrm{C}$ & 6.61 & 0.01 & 18.11 \\
$1 \% \mathrm{Ir} / \mathrm{C}$ & 1013.17 & 0.72 & 19.36 \\
$5 \% \mathrm{Rh} / \mathrm{C}$ & 803.22 & 0.56 & 19.28 \\
$3 \% \mathrm{Cu} / \mathrm{C}$ & 1270.90 & 1.01 & 19.31 \\
\hline
\end{tabular}

\subsection{SEM Results}

In the scanning electron microscopy (SEM) images of the catalyst materials, shown below, it can be seen that in the case of $\mathrm{Pd} / \mathrm{C}$, the carbon support consists of a mixture of sharp-edged needles with dimensions of up to $\sim 110 \mu \mathrm{m}$ in length and smaller particles down to the sub-micrometer scales. The larger particles have a T-shaped cross-section, where the middle bar was about $1.6 \mu \mathrm{m}$-wide and perpendicular to the $20 \mu \mathrm{m}$-wide base plate. At higher magnifications (i.e., 5000 and 10,000), it can be seen that the particles have a smooth surface and sharp edges and are plate-like in shape. The thickness of the particles 
was $1.6 \mu \mathrm{m}$ and the surface of the particle side was stepped parallel towards the longest particle axis. No pores could be seen with magnifications of up to 10,000 (see Figure 1d).

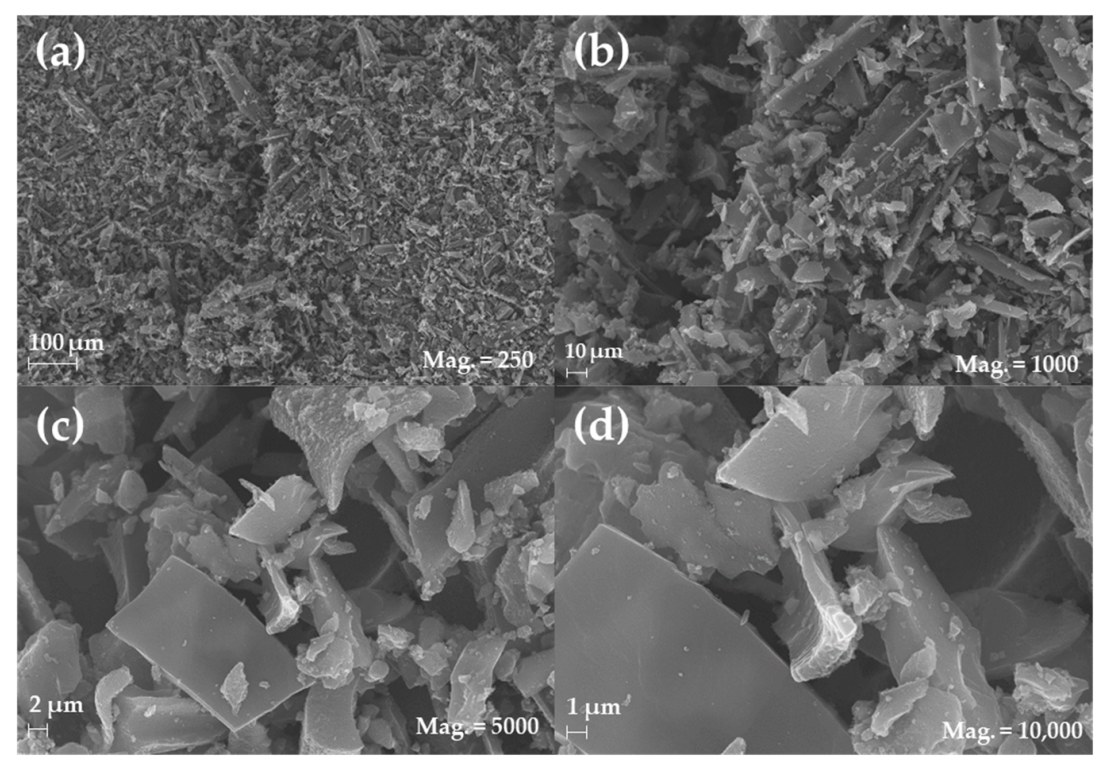

Figure 1. SEM images of 5\% Pd/C in magnifications from 250 to 10,000, (a-d). All images were taken with following parameters: $\mathrm{EHT}=20.0 \mathrm{kV}, \mathrm{WD}=8.5 \mathrm{~mm}$, SingalA $=$ InLens.

The particles of the $\mathrm{Pt} / \mathrm{C}$ catalyst are fairly similar to the already-described Pd catalyst (Figure $2 \mathrm{a}-\mathrm{d}$ ). The amount of long narrow particles with lengths of around $100 \mu \mathrm{m}$ and widths of $8 \mu \mathrm{m}$ was more prominent. In addition, the already-described T-shaped particles were more prominent, as can be seen in Figure 2d. Again, the perpendicular wall had a width particle thickness of $1.6 \mu \mathrm{m}$. The particle edges were very sharp and no pores could be seen at the highest magnifications.

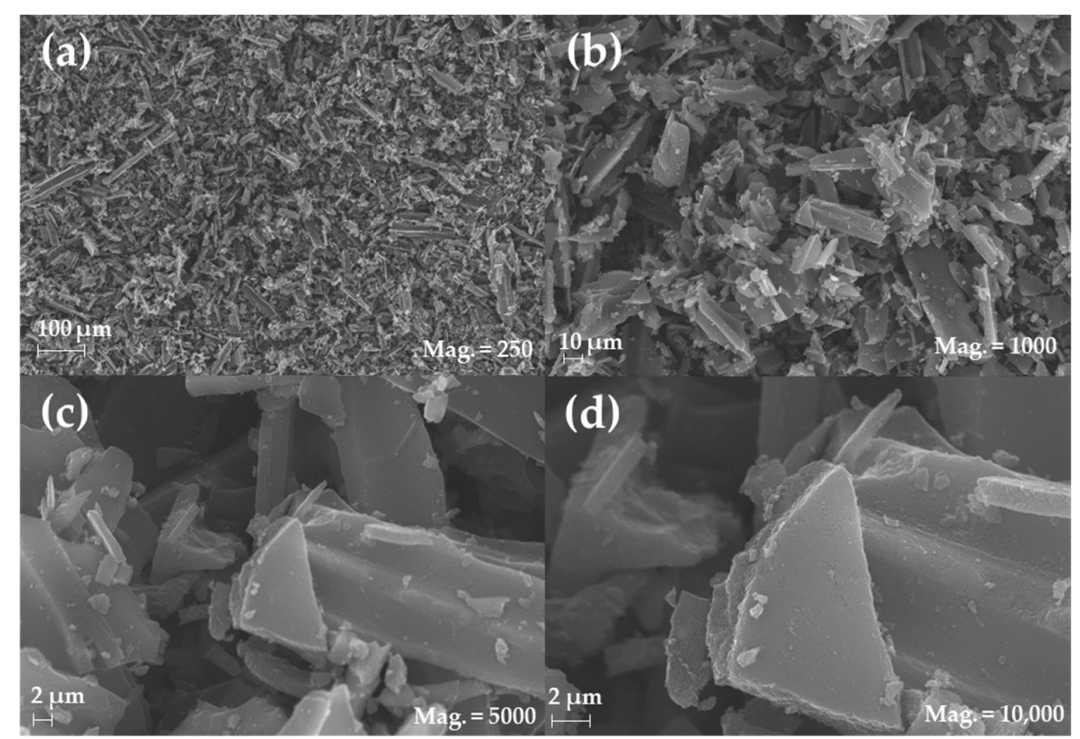

Figure 2. SEM images of 5\% Pt/C in magnifications from 250 to 10,000, (a-d). All images were taken with following parameters: $\mathrm{EHT}=20.0 \mathrm{kV}, \mathrm{WD}=8.5 \mathrm{~mm}$, SingalA = InLens.

For the $\mathrm{Ru} / \mathrm{C}$, the SEM images stand in contrast to the particles described above. At the lowest magnification, the particles are uniform in structure and size. At higher magnifications, it can be seen that they possess more rounded edges and that they are highly agglomerated in a hierarchical manner (see Figure $3 b$, top right and Figure $3 c, d$ ). 
The particles have a more round shape of $\sim 75 \mu \mathrm{m}$ in diameter (Figure 3b, top left). At the highest magnification, no pores could be detected and the hierarchical agglomerates were clearly visualized. The agglomerates consist of a base particle with a non-uniform shape (ca. $9.6 \mu \mathrm{m} \times 26.4 \mu \mathrm{m})$ topped by smaller non-uniform particles $(6-4 \mu \mathrm{m})$, which were supporting with dimensions smaller than $2 \mu \mathrm{m}$ (Figure 3c,d).

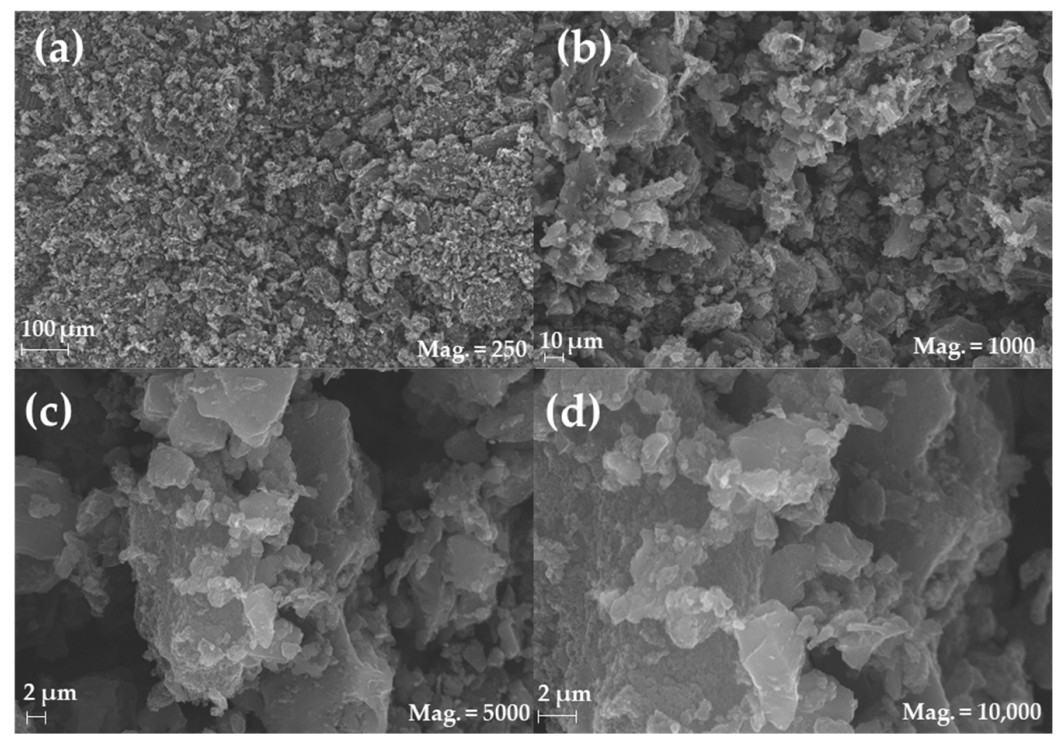

Figure 3. SEM images of 5\% Ru/C with magnifications from 250 to 10,000, (a-d). All images were taken with following parameters: $\mathrm{EHT}=20.0 \mathrm{kV}, \mathrm{WD}=8.5 \mathrm{~mm}$, SingalA $=$ InLens.

The SEM images of the Ir/C catalyst show an even distribution of particles with non-uniform shapes and a uniform size distribution. The particles were in the range of 9-25 $\mu \mathrm{m}$. At higher magnifications, it can be seen that the surface of particles with lengths of 25-32 $\mu \mathrm{m}$ and widths of $14 \mu \mathrm{m}$ is rough. These rough patches are similar in appearance to craters at magnifications of 50,000 and 100,000. The dimensions of these crater-like structures are in the range of $125-458 \mathrm{~nm}$, and they can be interpreted as pores (Figure $4 \mathrm{~d}$ ).

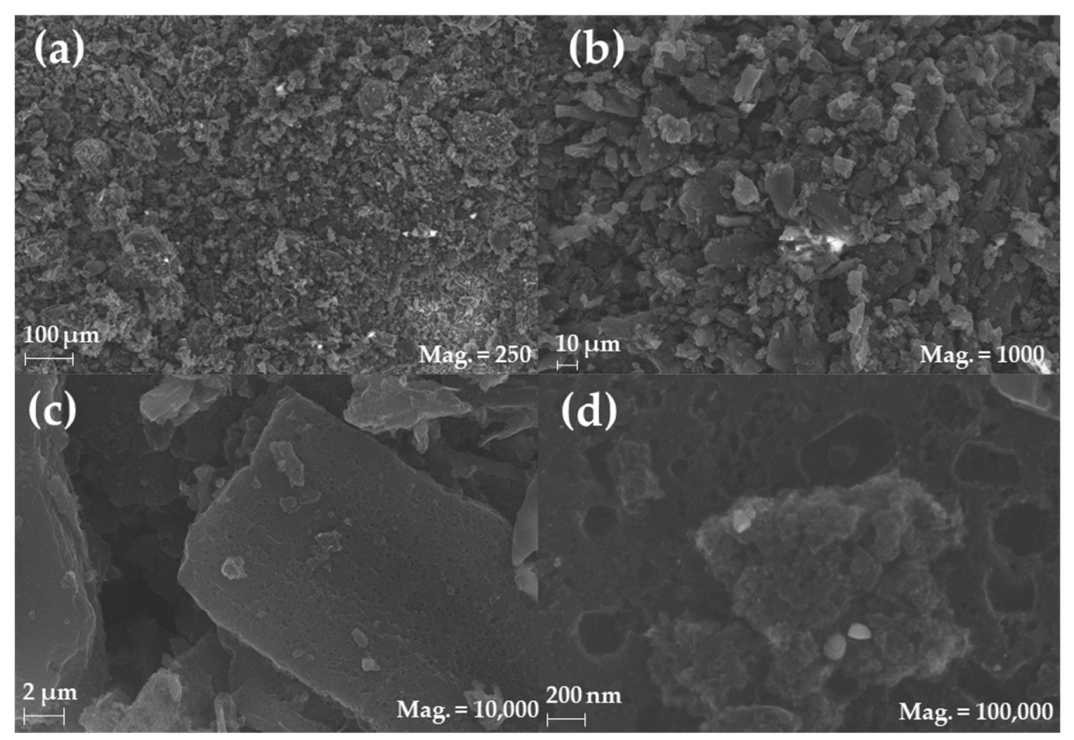

Figure 4. SEM images of the Ir/C catalyst with magnifications from 250 to 100,000, (a-d). All images were taken with following parameters: EHT $=20.0 \mathrm{kV}, \mathrm{WD}=8.5 \mathrm{~mm}$, SingalA $=$ InLens.

$\mathrm{Rh} / \mathrm{C}$ provides a uniform image of the SEM in Figure 5a,b. Grain sizes can hardly be established, as the particles have ragged edges and are heavily agglomerated. Even 
at magnifications of 5000, it is impossible for most dimensions to be determined due to the agglomeration of many small particles in the size range of 3.6-6.6 $\mu \mathrm{m}$. It becomes obvious at magnifications of 10,000 that the material consists of even smaller particles with a fairly narrow qualitative size distribution (see Figure $5 c, d$ ). At the highest magnification of 100,000, crater-like structures become visible at the particle surface that could be pore openings in the range of $25-100 \mathrm{~nm}$ in size. Overall, this material is made up of the smallest particles compared to all of the other catalytic materials considered in this study.

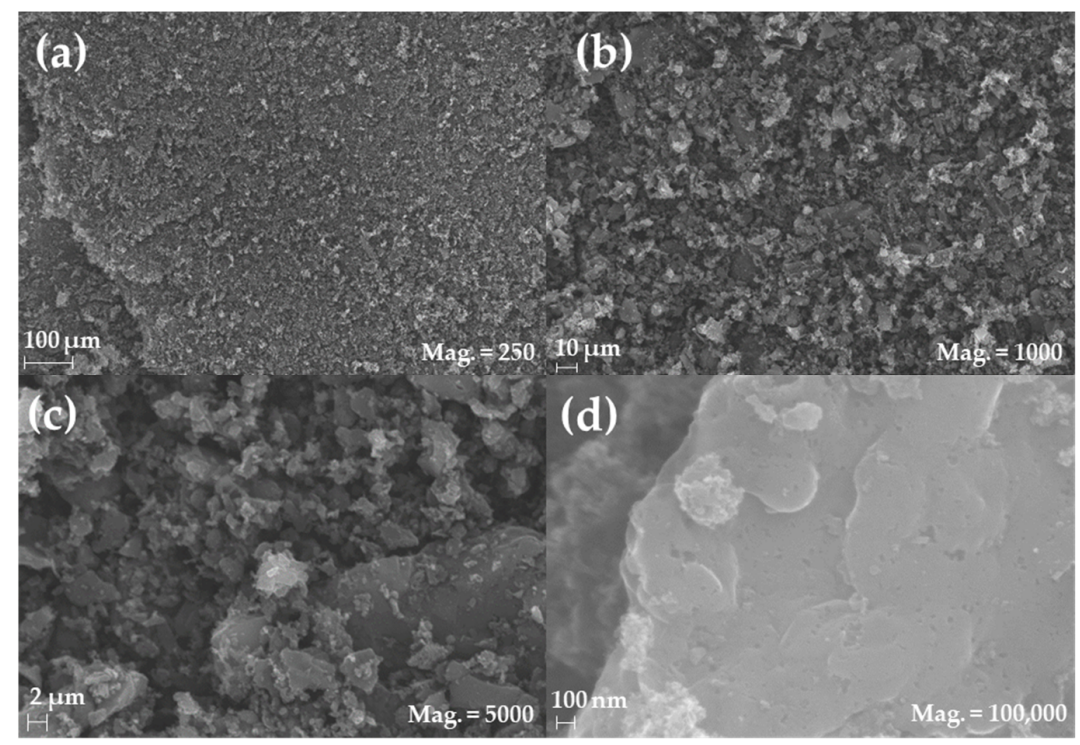

Figure 5. SEM images of the Rh/C catalyst, with magnifications from 250 to 10,000, (a-d). All images were taken with following parameters: EHT $=20.0 \mathrm{kV}, \mathrm{WD}=8.5 \mathrm{~mm}$, SingalA $=$ InLens.

Figure 6a shows the images of the $\mathrm{Cu} / \mathrm{C}$ catalyst. Particles with different shapes and dimensions of 36-181 $\mu \mathrm{m}$ stand clearly out from the smaller ones. These are made up of ragged non-uniform particles in the range of 22-36 $\mu \mathrm{m}$ and even smaller ones (Figure $6 \mathrm{~b}$ ). At higher magnifications, the particles exhibit a plate-shaped structure. This becomes very prominent at magnifications of 50,000. At the edges, the particles display a slate-like fracture. Pores cannot be seen, even at magnifications of up to 100,000.

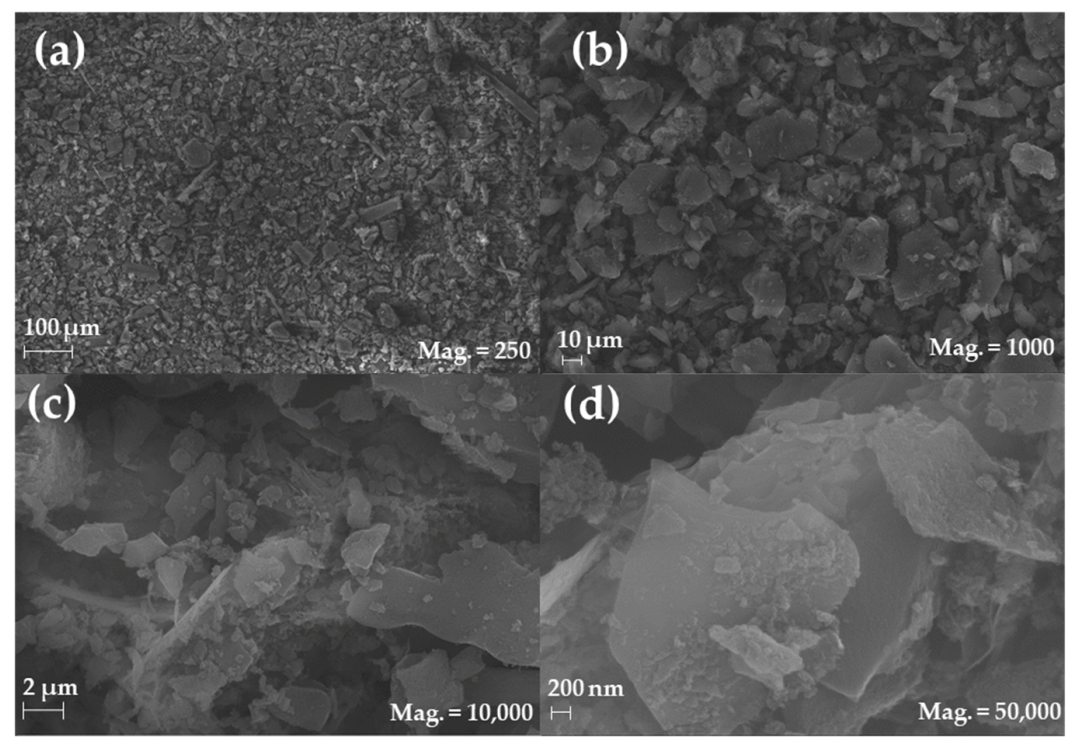

Figure 6. SEM images of the $\mathrm{Cu} / \mathrm{C}$ catalyst, with magnifications from 250 to 50,000, (a-d). All images were taken with following parameters: EHT $=20.0 \mathrm{kV}, \mathrm{WD}=8.5 \mathrm{~mm}$, SingalA $=$ InLens. 
Energy-dispersive X-ray (EDX) spectroscopy measurements were taken in order to establish an elemental analysis of the catalytic materials, the results of which are displayed in Table 2.

Although the nominal loadings of catalysts $\mathrm{Pd}, \mathrm{Ru}, \mathrm{Ir}$, and $\mathrm{Rh}$ are very close to the values found for those metals with the EDX mapping, $\mathrm{Pt}$ and $\mathrm{Cu}$ significantly deviate from those nominal loadings.

\subsection{TEM Results}

Figure 7 presents a Z-contrast, high-angle annular dark field (HAADF) STEM images, together with EDX elemental maps that illustrate the distribution of the $\mathrm{Rh}, \mathrm{Ru}$, and $\mathrm{Pd}$ catalyst nanoparticles on the $C$ support. Each row focuses on one catalyst, beginning with $\mathrm{Rh} / \mathrm{C}$ in row (a), followed by $\mathrm{Ru} / \mathrm{C}$ in row (b), and finally, $\mathrm{Pd} / \mathrm{C}$ in row (c). The left-hand-side images contain an overview of the catalysts on the $C$ support. The middle block contains HAADF images and the corresponding EDX map. Bright contrast features in the Z-contrast HAADF-STEM images correspond to the metal-rich nanoparticles (Rh, $\mathrm{Ru}$, and Pd-marked in green in the EDX maps). High-resolution (HR) HAADF cutouts with corresponding FFTs are placed on the right-hand-side section. Both $\mathrm{Rh}$ and $\mathrm{Pd}$ correspond to the face-centered crystals (FCCs), with images taken along the [011] zone axis. Meanwhile, the Ru nanoparticles exhibit poorer crystallinity [31].

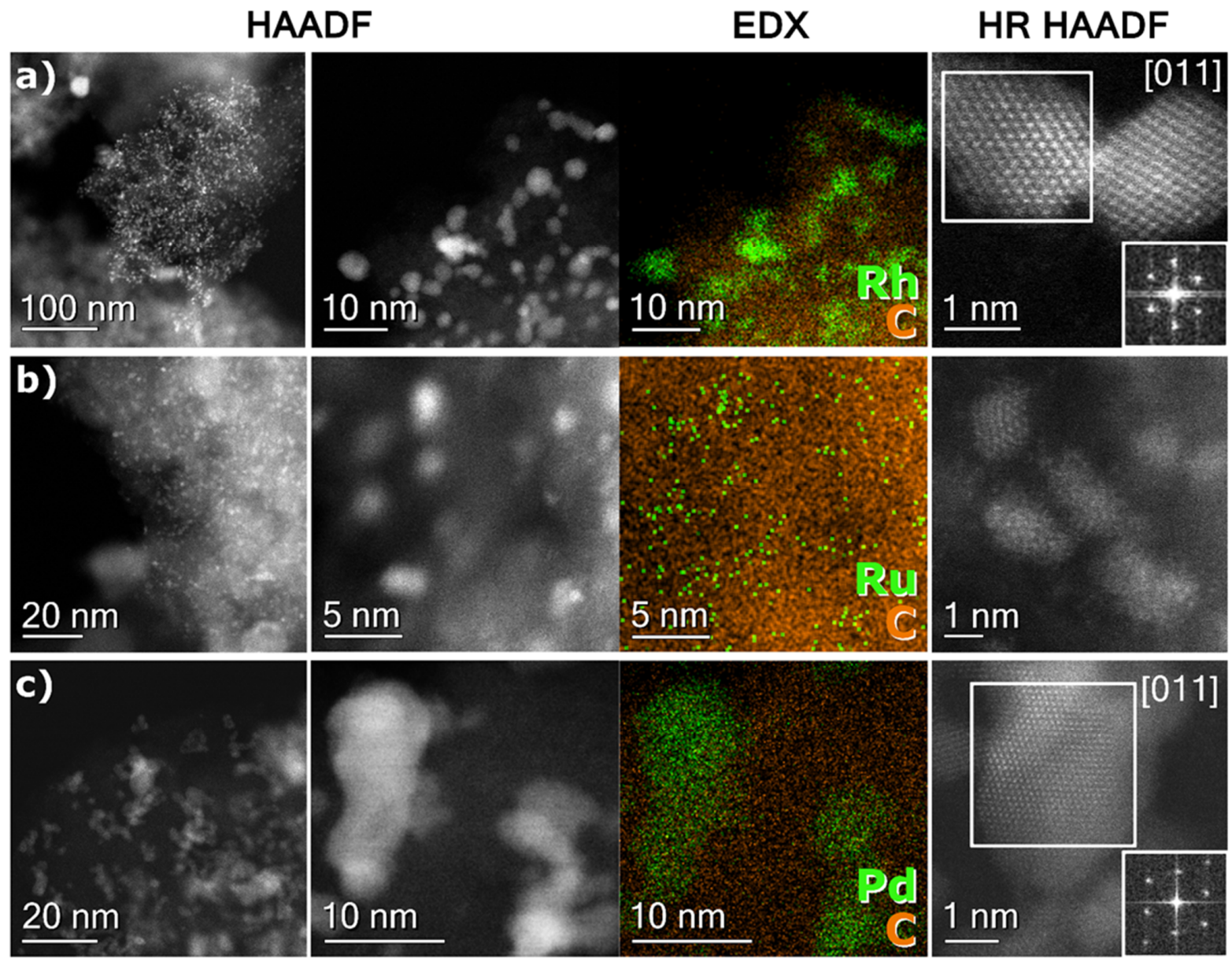

Figure 7. High-angle annular dark field (HAADF)-scanning transmission electron microscopy (STEM) images showing the distribution of the catalyst on the $\mathrm{C}$ support. Next to it, the survey images and corresponding EDX element maps display the orange-colored $\mathrm{C}$ support with the green-colored metals of the $\mathrm{Rh} / \mathrm{C}$ catalyst in row (a), the $\mathrm{Ru} / \mathrm{C}$ catalyst in row (b), and the Pd/C catalyst in row (c). The HR-HAADF-STEM images of single-catalyst nanoparticles are displayed on the right-hand side, with Fast Fourier Transform pattern inserts for Rh and Pd. Transmission electron microscope (TEM) images for $\mathrm{Pt} / \mathrm{C}, \mathrm{Ir} / \mathrm{C}$, and $\mathrm{Cu} / \mathrm{C}$ were also recently published [32]. 
Table 2. Results of the energy-dispersive X-ray (EDX) mapping.

\begin{tabular}{cccccccc}
\hline \multirow{2}{*}{ Catalyst $\mathbf{i}$} & EDX $(\mathbf{w t} \%)$ & - & - & - & - & - & - \\
\cline { 2 - 7 } & $\mathbf{C}$ & $\mathbf{O}$ & Metal i & Ca & Si & Al & P \\
\hline $\mathrm{Pd} / \mathrm{C}$ & $89.85 \pm 0.47$ & $6.24 \pm 0.13$ & $4.19 \pm 0.36$ & - & - & - & - \\
$\mathrm{Pt} / \mathrm{C}$ & $83.93 \pm 0.24$ & $7.95 \pm 0.23$ & $7.03 \pm 0.08$ & $1.10 \pm 0.03$ & - & - & - \\
$\mathrm{Ru} / \mathrm{C}$ & $86.80 \pm 0.32$ & $8.20 \pm 0.32$ & $4.45 \pm 0.17$ & - & $0.55 \pm 0.09$ & - & - \\
$\mathrm{Ir} / \mathrm{C}$ & $92.37 \pm 0.12$ & $5.72 \pm 0.19$ & $1.29 \pm 0.08$ & - & $0.62 \pm 0.01$ & - & - \\
$\mathrm{Rh} / \mathrm{C}$ & $87.93 \pm 0.39$ & $5.46 \pm 0.19$ & $6.05 \pm 0.20$ & - & $0.38 \pm 0.01$ & $0.19 \pm 0.01$ \\
$\mathrm{Cu} / \mathrm{C}$ & $86.40 \pm 0.33$ & $11.49 \pm 0.11$ & $1.6 \pm 0.21$ & - & - & - & $0.52 \pm 0.04$ \\
\hline
\end{tabular}

\section{4. $\mathrm{H}_{2}$ Chemisorption Results}

Despite the challenges associated with surface area determination by means of chemis orption methods, we attempted to measure the surface areas of the catalysts using dynamic flow methods, namely the pulse chemisorption of hydrogen in argon. The results are listed in Table 3.The mean particle size found for the Pt/C catalyst was $2.2 \mathrm{~nm}$. The catalyst exhibited a decent dispersion of $46 \%$, and the largest metal surface area found for all of the catalysts considered in this study. $\mathrm{Ru} / \mathrm{C}$ and $\mathrm{Rh} / \mathrm{C}$ showed lower dispersions, with mean particle diameters of 2.5 and $4.5 \mathrm{~nm}$. Even though we employed a stoichiometric factor of $\mathrm{H}^{*}: \mathrm{M}_{\mathrm{s}}=1$, we found the results to be in good agreement with the particle sizes established by means of TEM.

Table 3. Results of the H-chemisorption experiments. The stoichiometric factor of $\mathrm{H}^{*}: \mathrm{M}_{\mathrm{S}}$ chosen was 1. The data for $\mathrm{Cu} / \mathrm{C}$ was determined by oxygen titration.

\begin{tabular}{cccccc}
\hline & \multicolumn{2}{c}{ Specific $\mathbf{A}_{\text {metal }}$} & D & $\mathbf{d}_{\text {chemisorption }}$ & $\mathbf{d}_{\text {TEM }}$ \\
\hline & $\mathbf{m}^{\mathbf{2}} / \mathbf{g}_{\text {Sample }}$ & $\mathbf{m}^{\mathbf{2}} / \mathbf{g}_{\text {metal }}$ & $\mathbf{\%}$ & $\mathbf{n m}$ & $\mathbf{n m}$ \\
\hline $\mathrm{Pt} / \mathrm{C}$ & 8.97 & 127.5 & 46 & 2.2 & 2.3 \\
$\mathrm{Ru} / \mathrm{C}$ & 8.58 & 192.8 & 36 & 2.5 & 2.1 \\
$\mathrm{Rh} / \mathrm{C}$ & 6.54 & 108.2 & 24 & 4.5 & 2.6 \\
$\mathrm{Ir} / \mathrm{C}$ & 2.59 & 200.7 & 53 & 1.3 & 2.3 \\
$\mathrm{Pd} / \mathrm{C}$ & 7.07 & 168.7 & 38 & 3.0 & 3.2 \\
$\mathrm{Cu} / \mathrm{C}$ & 0.63 & 39.2 & 6 & 17.1 & 6.1 \\
\hline
\end{tabular}

The mean particle sizes calculated for the Ir/C catalyst were the smallest, with a mean diameter of $1.3 \mathrm{~nm}$, which is smaller than what was found during the TEM examination. This is likely due to the use of a stoichiometric factor of adsorbed hydrogen/surface metal of 1. Almithn and Hibbitts calculated the stoichiometric factors for hydrogen adsorption for Ir and Pt as 1.84 to 3.63, respectively, for mean particle sizes of 2.4 to $0.8 \mathrm{~nm}$ [33]. They showed in their density-functional theory (DFT) calculations that bulk $\mathrm{H}^{*}$ species are not to be expected for those metals, but that under-saturated atoms, in particular, bind to more than one hydrogen atom each. Therefore, with smaller particles, the stoichiometric factor increases. This is also in line with several experimental findings and well-established [34,35].

For $\mathrm{Pd} / \mathrm{C}$, hydrogen adsorption is of crucial importance at room temperature due to the well-known formation of subsurface hydrogen species and bulk hydrides. Although these are later kinetically limited to form at $130 \mathrm{~K}$, subsurface hydrogen species can increase the H:MS ratio. This in turn can result in an underestimation of particle size [36]. Nevertheless, we found our estimations of particle size for the $\mathrm{Pd} / \mathrm{C}$ to be reasonable in light of the TEM results.

The particle size determination of $\mathrm{Cu} / \mathrm{C}$ was performed using a different method. As is well-known, $\mathrm{O}_{2}$ readily dissociates on copper surfaces with very low energy barriers [37]. Therefore, we saturated the freshly reduced $\mathrm{Cu} / \mathrm{C}$ surface with oxygen at $323 \mathrm{~K}$ and allowed for the desorption of physisorbed oxygen in the flowing argon at $333 \mathrm{~K}$ while preventing bulk oxidation that is known to take place in $\mathrm{N}_{2} \mathrm{O}$ adsorptive decomposition between 303 and $323 \mathrm{~K}$ and thus increases the activation energies for bulk oxidation [37,38]. Pulses of 
fixed amounts of pure hydrogen at $673 \mathrm{~K}$ were used to titrate back the oxidized copper atoms. The calculations established a mean particle diameter of $17 \mathrm{~nm}$. These results deviate heavily from the TEM measurements, whereas they correspond to previously published TEM results [32]. The deviation can be explained by taking into account the local formation of large $\mathrm{Cu}$-rich agglomerates. Furthermore, only a relatively small number of measurements could be taken by TEM for particle size analysis (see Supplementary Materials Figure S3). Therefore, the determined TEM particle size must be accepted with caution. The particle size estimated by chemisorption is strongly dependent on the determined $\mathrm{Cu}$-loading. As the loading was established by means of EDX, a difference in loading could also account for the highly deviating particle size.

\subsection{Catalytic Experiments}

In all catalytic experiments, which are summarized in Table 4, i-butanol was formed in differing quantities. Due to the absence of strongly acidic or basic centers in the carbon support acetyls, ethers and esters were not detected in the experiment, although they are common side-products described in the literature and strongly correlate to the basic sites prominent in the catalyst supports or bases used [2,3]. In light of the experimental conditions, these products have a very small tendency to form and, in the case of acetyls and esters, will be decomposed by sodium hydroxide. The yields of i-butanol were very low, as differential conditions were chosen in order to gather information about catalyst deactivation over time, which will be discussed below.

Based on the liquid products formed in the reaction, $\mathrm{Pt} / \mathrm{C}$ offered the highest yield of i-butanol after the reaction time with good selectivity (89\%) towards i-butanol. $\mathrm{Ru} / \mathrm{C}$ also showed comparable yields of i-butanol, but with only slightly lesser selectivity. Both catalysts formed similar amounts of n-propanol during the reaction. When normalized to the utilized catalyst dry weights, the calculated space-time yields (STY) clearly exhibited a higher efficiency of the $\mathrm{Pt} / \mathrm{C}$ catalyst with respect to the $\mathrm{Ru} / \mathrm{C}$ one. This was also represented by the turnover frequencies (TOFs).

$\mathrm{Rh} / \mathrm{C}$ and $\mathrm{Pd} / \mathrm{C}$ also presented decent yields of i-butanol, whereas the selectivity was lower for the $\mathrm{Rh} / \mathrm{C}$ catalyst. This was due to the formation of n-butanol and croton aldehyde with very low yields and selectivities. These are the products of ethanol homo coupling, which were only present in the experiments with the $\mathrm{Rh} / \mathrm{C}$ catalyst.

Ir/C produced fairly remarkable yields of i-butanol and a good STY, taking into account that the loading of the catalyst was only $1.29 \%$. From Table 3, it can be seen that the dispersion of the Ir particles was the highest among all of the catalysts. This in turn led to the surface Ir atoms having a high degree of accessibility. The TOF of the Ir/C for the formation of i-butanol was $6.8 \mathrm{~h}^{-1}$. Only $\mathrm{Cu} / \mathrm{C}$ yielded less i-butanol $(0.1 \%$; selectivity: $19 \%)$, but presented the highest yields of acetaldehyde with high selectivity $(80 \%)$. This accords with the consensus in the literature that $\mathrm{Cu}$ exhibits a high selectivity regarding acetaldehyde formation [39-44].

Table 4. Results of the catalytic tests: $\mathrm{t}$ (Reaction $)=4 \mathrm{~h}, \mathrm{~T}=150^{\circ} \mathrm{C}, \mathrm{m}$ (Catalyst, wet $)=250 \mathrm{mg}, \mathrm{c}(\mathrm{NaOH})=450 \mathrm{mmol} / \mathrm{L}$, $\mathrm{c}(\mathrm{EtOH})=600 \mathrm{mmol} / \mathrm{L}$.

\begin{tabular}{|c|c|c|c|c|c|c|c|c|c|}
\hline \multirow[t]{2}{*}{ Entry } & \multirow[t]{2}{*}{ Catalyst } & \multirow{2}{*}{$\begin{array}{l}\text { EDX } \\
w t \%\end{array}$} & \multirow{2}{*}{$\frac{\varepsilon(d)^{d}}{e V}$} & \multirow{2}{*}{$\begin{array}{c}\text { STY } \\
\mathrm{mmolh}^{-1} \mathrm{~g}^{-1}\end{array}$} & \multirow{2}{*}{$\begin{array}{l}\text { TOF } \\
h^{-1}\end{array}$} & \multicolumn{4}{|c|}{ Yield (Selectivity ${ }^{a}$ ) in $\%$} \\
\hline & & & & & & Acetaldehyde & Propanal & n-Propanol & i-Butanol \\
\hline 1 & 5\% Ru/C & 4.45 & -1.41 & 1.47 & 9.29 & - & - & $0.27(13.36)$ & $1.77(86.64)$ \\
\hline 2 & $5 \% \mathrm{Rh} / \mathrm{C}^{\mathrm{b}}$ & 6.05 & -1.73 & 0.04 & 2.62 & - & $0.21(27.89)$ & - & $0.69(60.94)$ \\
\hline 3 & $5 \% \mathrm{Pd} / \mathrm{C}$ & 4.19 & -1.83 & 0.10 & 6.44 & - & - & $0.31(28.01)$ & $0.81(71.44)$ \\
\hline 4 & $5 \% \mathrm{Pt} / \mathrm{C}$ & 7.03 & -2.25 & 2.72 & 16.25 & - & - & 0.25 (11.07) & 1.99 (88.93) \\
\hline 5 & $1 \% \operatorname{Ir} / \mathrm{C}$ & 1.29 & -2.11 & 0.34 & 9.58 & $0.03(8.53)$ & - & - & 0.27 (91.47) \\
\hline 6 & $1 \% \operatorname{Ir} / \mathrm{C}^{\mathrm{c}}$ & 1.29 & -2.11 & 0.14 & 2.10 & $0.04(22.85)$ & - & - & $0.15(77.15)$ \\
\hline 7 & $3 \% \mathrm{Cu} / \mathrm{C}$ & 1.60 & -2.67 & 0.07 & 4.83 & $0.54(79.51)$ & $0.002(0.25)$ & $0.01(1.40)$ & $0.13(18.85)$ \\
\hline 8 & $3 \% \mathrm{Cu} / \mathrm{C}^{\mathrm{c}}$ & 1.60 & -2.67 & 0.06 & 3.96 & $0.14(66.16)$ & - & - & $0.07(33.84)$ \\
\hline
\end{tabular}

${ }^{a}$ Selectivity calculated based on only the fraction of liquid products. ${ }^{\mathrm{b}} \mathrm{Rh} / \mathrm{C}$ only: Yield (selectivity) of n-butanol: $0.04(5.13) \%$; croton aldehyde: $0.05(6.02) \% .{ }^{c}$ Catalysts reduced prior to testing in the autoclave; $\mathrm{p}\left(\mathrm{H}_{2}\right)=40$ bar; $\mathrm{t}_{\text {Reduction }}=1 \mathrm{~h} ; \mathrm{T}_{\text {Reduction }}=250{ }^{\circ} \mathrm{C}$. ${ }^{\mathrm{d}} \mathrm{d}-\mathrm{band}$ center values from Hammer et al. [45]. 
The EDX mapping of the $\mathrm{Ir} / \mathrm{C}$ and $\mathrm{Cu} / \mathrm{C}$ catalysts revealed oxygen in higher concentrations within the metal-rich particles. In order to rule out that the low activity of $\mathrm{Cu} / \mathrm{C}$ and $\mathrm{Ir} / \mathrm{C}$ was due to the presence of metal oxide, they were reduced (at $250^{\circ} \mathrm{C}$ for $1 \mathrm{~h}$ at 40 bar of hydrogen atmosphere) prior to the catalytic tests (see Table 4 , entries 6 and 8). Following pretreatment, the autoclave was cooled back to room temperature and the atmosphere was exchanged with nitrogen. The reactor was then charged with the reaction solution through a septum and the standard reaction protocol was performed. Although a reduction in the metals should be achievable in those conditions, the activity of the catalysts did not increase, but instead further decreased.

For Ir/C, the yield of i-butanol was almost twice as high without hydrogen pretreatment and only a small amount of n-propanol could be detected. The selectivity towards i-butanol was $89.03 \%$ for the untreated catalyst and $77.15 \%$ for the reduced one. In addition, no n-propanol could be observed for the reduced catalyst. The yield of acetaldehyde, on the other hand, increased for the pre-reduced catalyst, leading to a selectivity of $22.85 \%$ for acetaldehyde. The same trend held true for the reduced $\mathrm{Cu} / \mathrm{C}$ catalyst. With the hydrogen treatment, the yields of i-butanol dropped from $0.13 \%$ to $0.07 \%$. Contrary to the $\mathrm{Ir} / \mathrm{C}$ catalyst for the $\mathrm{Cu} / \mathrm{C}$, small amounts of propanal could be detected and high selectivity was noted for acetaldehyde $(79.51 \%)$ without hydrogen pretreatment. The TOF only slightly decreased for the reduced $\mathrm{Cu} / \mathrm{C}$ catalyst.

For both materials, the resulting TOF was reduced by comparison to the untreated catalysts. It can, therefore, be determined that the low activity of the copper and iridium was due to oxide formation. This cannot be ruled out as promoting the sintering of particles with pretreatment, but to the best of our knowledge, it is unlikely to be the reason for the reduced TOFs. Borsay et al. showed that carbon-supported $\mathrm{Cu}$ nanoparticles with diameters larger than $8 \mathrm{~nm}$ are stable up to $320^{\circ} \mathrm{C}$ and redisperse partially under reducing atmospheres [46]. The particles observed in the TEM measurements had a mean diameter of $6 \mathrm{~nm}$ and chemisorption particles had diameters of ca. $17 \mathrm{~nm}$ and should therefore be stable against sintering under pretreatment conditions. From scanning transmission electron microscopy (STEM) experiments, it is known that ethanol and methanol are adsorbed onto $\mathrm{Cu}(111)$ and $\mathrm{Cu}(110)$ surfaces and subsequent dehydrogenation is promoted by surface oxygen or water. Pre-reduction in the surface, therefore, reduces the rate of ethanol and methanol dehydrogenation [47-50]. Therefore, we conclude that the reduced TOF is due to the reduction in surface oxides that aid ethanol dehydrogenation on $\mathrm{Cu}$ surfaces and are removed during the pretreatment process. In accordance with the calculations by Wanke et al., the sintering of Ir particles under those conditions is even more unlikely due to lower self-diffusion coefficients and higher activation barriers for surface diffusion resulting from a higher melting points of iridium by comparison to copper [51]. Additionally, Ir particles with a $2 \mathrm{~nm}$ diameter have even been synthesized at $800^{\circ} \mathrm{C}$ on carbon support over $3 \mathrm{~h} \mathrm{[52]}$ and $\mathrm{Xu}$ et al. presented evidence that the superior activity of their catalysts was due to $\mathrm{Ir}$ oxide species [53].

Figure 8 shows the concentration of i-butanol plotted against the reaction time in hours. The experiments were normalized for $0.100 \mathrm{~g}$ dry mass of the catalyst. In that manner, the concentrations obtained with different catalyst masses could be compared. Figure 8a displays an overview of the entire reaction time. As is also depicted in Figure 8a, platinum underwent a steep increase in i-butanol concentration. With ongoing reaction time, the rate clearly decreased after $2 \mathrm{~h}$ of reaction time. As the reaction was performed under differential conditions, the conversion was below $2 \%$, meaning that an equilibrium could not be reached at this point. $\mathrm{Pt} / \mathrm{C}$ reaches the highest concentration of i-butanol at $14.4 \mathrm{mmol} / \mathrm{L}$ after $4 \mathrm{~h}$ reaction time, with an initial STY of $3.10 \pm 0.14 \mathrm{mmol} \cdot \mathrm{h}^{-1} \mathrm{~g}_{\text {cat }}{ }^{-1}$ that decreases to $2.33 \pm 0.05 \mathrm{mmol} \cdot \mathrm{h}^{-1} \mathrm{~g}_{\mathrm{cat}}{ }^{-1}$ over $4 \mathrm{~h}$. Ir $/ \mathrm{C}$ and $\mathrm{Pd} / \mathrm{C}$ exhibit similar deactivation trends with lower mean STYs than Pt/C. As can be seen in Figure $8 b, \mathrm{Pt} / \mathrm{C}, \mathrm{Ru} / \mathrm{C}, \mathrm{Pd} / \mathrm{C}$, and $\mathrm{Ir} / \mathrm{C}$ already form i-butanol during the heating up period. At $150{ }^{\circ} \mathrm{C}, \mathrm{Pd} / \mathrm{C}$ showed a good increase in the i-butanol concentration at first, but then a strong decrease in the rate of formation occurred, reaching a yield of $0.80 \%$ of $\mathrm{i}$-butanol after $4 \mathrm{~h}$ of reaction time. For $\mathrm{Pd} / \mathrm{C}$, the decrease 
in STY was more prominent with a decrease from $1.30 \pm 0.03 \mathrm{mmol} \cdot \mathrm{h}^{-1} \mathrm{~g}_{\text {cat }}{ }^{-1}$ after $1 \mathrm{~h}$ to $0.74 \pm 0.02 \mathrm{mmol} \cdot \mathrm{h}^{-1} \mathrm{~g}_{\text {cat }}{ }^{-1}$ after $4 \mathrm{~h}$ of reaction time, although $\mathrm{Ir} / \mathrm{C}$ only underwent an overall decrease from $0.44 \pm 0.03$ to $0.28 \pm 0.003 \mathrm{mmol} \cdot \mathrm{h}^{-1} \mathrm{~g}_{\text {cat }}{ }^{-1}$.

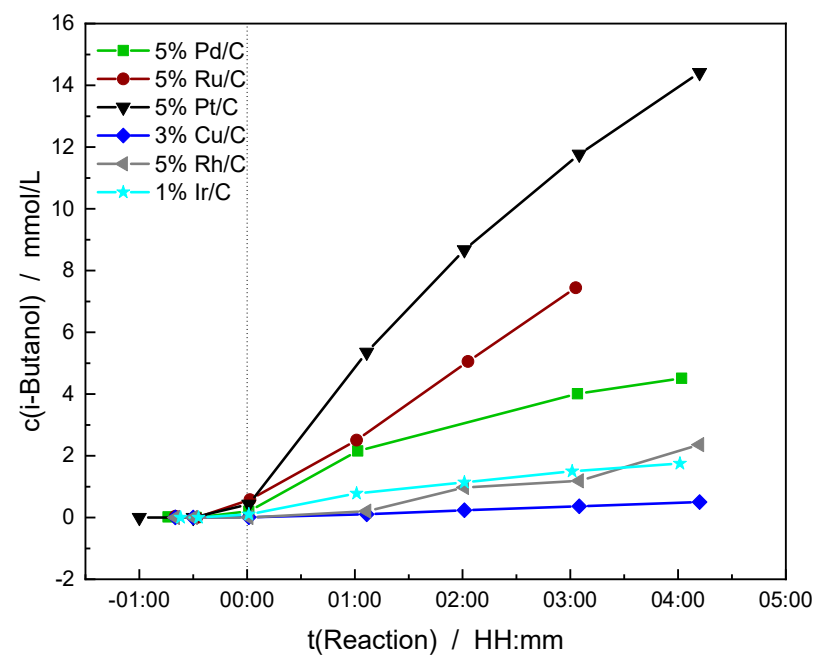

(a)

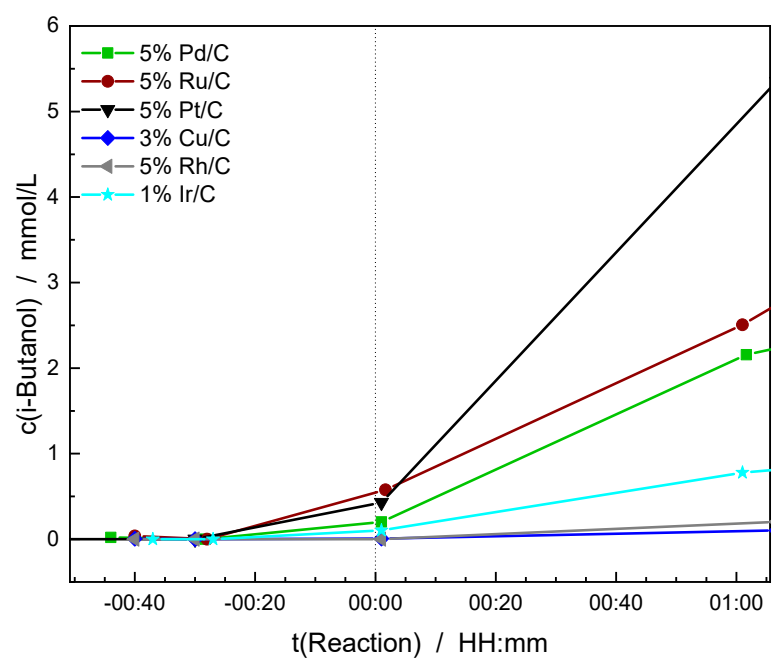

(b)

Figure 8. $\mathrm{c}(\mathrm{i}-\mathrm{Butanol})$ plotted against the reaction time for all catalysts. $\mathrm{t}$ (Reaction) $=4 \mathrm{~h}, \mathrm{~T}=150{ }^{\circ} \mathrm{C}, \mathrm{N}=1000 \mathrm{RPM}$, $\mathrm{V}=70 \mathrm{~mL}$, and $\mathrm{m}$ (catalyst) $=0.1 \mathrm{~g}$. (a) Overview of the entire reaction time and (b) enlarged for the heating-up period. The dotted line marks the point at which $150{ }^{\circ} \mathrm{C}$ was reached.

For $\mathrm{Pt} / \mathrm{C}$, we were able to prove a deposition of carbonaceous matter on the catalyst by pulsing the catalyst with ethanol under ultra-high vacuum (UHV) conditions, as recently published [32]. Taking into account the pressure gap, we anticipate coking processes to have been a reason for the catalyst deactivation. Clarifying these deactivation processes is a goal of future research, especially as $\mathrm{Ru} / \mathrm{C}, \mathrm{Rh} / \mathrm{C}$, and $\mathrm{Cu} / \mathrm{C}$ did not exhibit these deactivation processes. In the beginning, for $\mathrm{Ru} / \mathrm{C}$, a STY of $1.31 \pm 0.23 \mathrm{mmol} \cdot \mathrm{h}^{-1} \mathrm{~g}_{\text {cat }}{ }^{-1}$ at $1 \mathrm{~h}$ was measured. Taking into account the error limit, after $4 \mathrm{~h}$, the STY was equal $\left(1.57 \pm 0.04 \mathrm{mmol} \cdot \mathrm{h}^{-1} \mathrm{~g}_{\text {cat }}{ }^{-1}\right)$ and could therefore be regarded as constant. As the reaction solution of the $\mathrm{Ru} / \mathrm{C}$ catalyst had a slight brown color, we suspected that the catalyst was prone to leaching. ICP-OES measurements of the filtered reaction solution showed clear evidence that some amount of the catalyst dissolved into the reaction solution. The catalysts of $\mathrm{Cu}$ and $\mathrm{Rh}$ showed an initiation phase in which no i-butanol was detected by gas chromatography-mass spectrometry (GC-MS). After 2 h, i-butanol could be detected for all catalysts. The reaction rates followed a similar trend for all of these catalysts, as they possessed a more or less stable reaction rate with respect to i-butanol.

In order to correlate the chemical properties of the metals with their electronic structures, we correlated the TOF to their d-band centers. Figure 9 displays these results plotted against the d-band centers of the metals as calculated by Hammer and Nørskov [45] and shows that the TOF of the metals plotted against the d-band centers results in a volcano plot. Platinum represents the optimum in this curve. The activity of the metals for i-butanol synthesis is: $\mathrm{Cu}<\mathrm{Pt}>\mathrm{Ir}>\mathrm{Pd}>\mathrm{Rh}$, where the d-band center increases from $\mathrm{Cu}$ to $\mathrm{Rh}$. The ruthenium catalyst does not precisely follow this trend. As leaching of the catalyst was proven, the TOF based on surface metal atoms is likely to be overestimated, as redispersion or catalytic activity of the dissolved ruthenium ions cannot be excluded. For better visibility, a line has been drawn to make the trend easier to discern. 


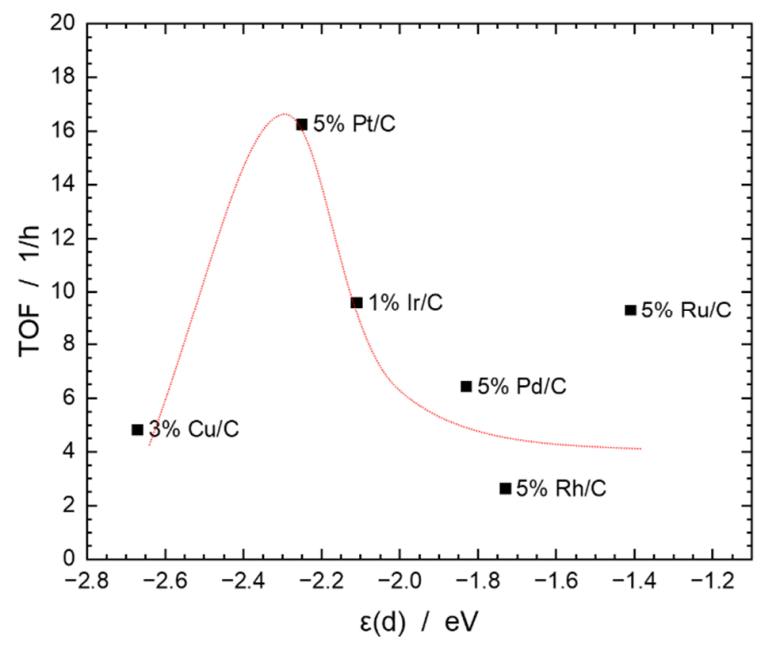

Figure 9. Resulting volcano plot for the turnover frequency (TOF) of the transition metal catalysts in the i-butanol synthesis. The red curve was drawn for the purpose of clarity.

As explained in the introduction, the d-band center correlates with the bond strength to a surface adsorbate [18]. In the i-butanol synthesis, different intermediates are produced, by bond cleavage $(\mathrm{O}-\mathrm{H}, \mathrm{H}-\mathrm{H}, \mathrm{C}-\mathrm{H})$ and formation of new bonds $(\mathrm{C}-\mathrm{C}, \mathrm{C}-\mathrm{H}, \mathrm{O}-\mathrm{H})[24,32]$. Every intermediate possesses different molecular orbital energies. The overlap of the corresponding molecular orbitals with the metal surface orbitals leads to bonding and antibonding states. Therefore, the low-lying d-band of copper will lead to antibonding states closer to the fermi level with a higher occupancy. This in turn will weaken the surfacemolecule interaction leading to only a few activated molecules. Moving to higher d-band centers leads to a lower occupancy of the higher lying antibonding states, thereby increasing adsorbate-surface interactions. Therefore, desorption energies of the intermediates will be high, reducing the amount of free surface sites, thus reducing the TOF due to strongly adsorbed species. Platinum possesses the most optimal d-band center in this series of catalysts, which allows for good metal-molecule interactions without the blocking of active sites due to strongly adsorbed species.

In order to correlate our findings with the data in the literature, we drew on the results of the c-methylation experiments by Siddiki et al. [24]. In Figure 10, the calculated TOFs are plotted against the d-band center of the transition metals.

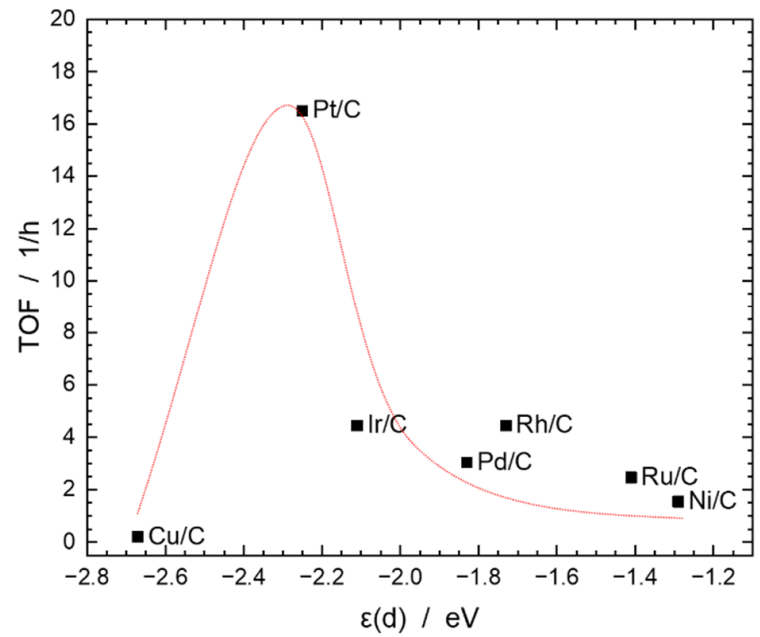

Figure 10. Resulting volcano plot for the TOF of the transition metal catalysts in the $\beta$-methylation of 2-phenyletahanol. $\mathrm{T}=120^{\circ} \mathrm{C}, 1.5$ equiv. $\mathrm{NaOH}$, and $\mathrm{t}$ (Reaction) $=24 \mathrm{~h}$. The red curve was drawn for the purpose of clarity. 
From Figure 10, it can be concluded that also in the $\beta$-methylation of 2-phenylethanol by Siddiki et al., the transition metals follow the same trend. Although the TOFs are fairly similar for the platinum catalyst, in Siddiki's measurements, $\mathrm{Cu}$, Ir, Pd, and Ru have lower TOFs. Although the general trend is in good agreement with our findings, we attribute this to two main factors.

First, differences in the absolute number of TOFs can be explained by differences in the substrate, as Siddiki et al. also observed different conversions for different substrates. In general, higher acidic substrates such as the phenyl alcohols are converted to a greater extent than less acidic ones like aliphatic alcohols. Second, our experiments were performed with lower base concentrations and at higher temperatures than in Siddiki's experiments. Siddiki explained the activity trends of the transition metals in terms of the calculated adsorption energy for hydrogen in a $\mu_{3}$-capping position on the most stable metal surface. This does not take into account the size effects of the metal particles, as adsorption energies change with the binding position and particle size [33]. By plotting the TOF against the $\mathrm{d}$-band center of the bulk metal, we also ignored the influence of particle size. However, to our understanding, the d-band center is independent of the particle dimension, as the dispersion of the d-band does not change due to size, but orbital overlap [54]. Although $\mathrm{Ni} / \mathrm{C}$ seemed not very well-described by plotting the hydrogen adsorption energies against the activity of the metal, its activity fitted the trend when plotted against the d-band center.

\section{Materials and Methods}

All chemicals were used without undergoing further purification.

\subsection{STEM Measurements}

The powder samples were prepared on a Cu-film grid and two STEM images were taken to capture the distribution of the catalyst within the carbon support, as well as its size. High-angle annular dark field (HAADF) images, conjointly with EDX elemental mapping, are presented here. $\mathrm{Ru}$ and $\mathrm{Rh}$ were investigated by means of an aberration-corrected FEI Titan G2 80-200 STEM field emission electron microscope at $200 \mathrm{eV}$ with a Super-X EDX system [55]. For Pd, a probe-corrected cold FEG STEM Hitachi HF5000 electron microscope at $200 \mathrm{eV}$ was used.

\subsection{XRD Measurements}

XRD measurements were performed using a Bruker D8 Discover and then measured with $\mathrm{Cu}(\mathrm{K} \alpha)=1.5418 \AA$ (tube voltage: $40 \mathrm{kV}$; current $=40 \mathrm{~mA}$ ) with no Ni-filters from $10^{\circ}$ to $90^{\circ}$ and a step width of $0.00806^{\circ}$ and a rate of $1 \mathrm{~s} / \mathrm{step}$.

\subsection{Catalytic Experiments}

Catalytic experiments were performed in a Parr autoclave equipped with a $100 \mathrm{~mL}$ alloy 600 vessel, an internal impeller stirrer, and a thermometer. The samples were then drawn though a 1/16" alloy 600 capillary attached to the autoclave. For a typical experiment, the autoclave was charged with $70 \mathrm{~mL}$ of a methanol solution (p.A., Merck KGaA, Darmstadt, HE, Germany) containing ethanol (600 mmol/L, ph. Eur, Merck KGaA, Darmstadt, HE, Germany), NaOH (450 mmol/L, 97\%, Fisher Scientific GmbH, Schwerte, NRW, Germany), and n-dodecane (15 mmol/L, internal standard, 99\%, Merck KGaA, Darmstadt, HE, Germany). Further, $250 \mathrm{mg}$ of catalyst was added before closing the autoclave and exchanging the air by pressuring the autoclave three times with $5.5 \mathrm{bar}$ of nitrogen. The reaction itself was performed under autogenous pressure at $150{ }^{\circ} \mathrm{C}$ for $4 \mathrm{~h}$.

The samples were prepared for measurement by means of the full evaporation technique. Every $60 \mathrm{~min}, 1 \mathrm{~mL}$ of sample was drawn through the capillary from the reaction and $3 \mu \mathrm{L}$ was transferred to a $21 \mathrm{~mL}$ headspace vial. Every sample point was then measured three times. In order to ensure full evaporation, the vial was placed in an oven at $100{ }^{\circ} \mathrm{C}$ for $4 \mathrm{~min}$ and an aliquot of $0.5 \mathrm{~mL}$ was injected using the injection system (a 
PAL HTS syringe; temperature: $110{ }^{\circ} \mathrm{C}$, fill speed $=100 \mu \mathrm{L} / \mathrm{s}$; pull-up delay $=1000 \mathrm{~ms}$; injection speed $=500 \mu \mathrm{L} / \mathrm{s}$; pre $/$ post-delay $=500 \mathrm{~ms}$; flush time $=20 \mathrm{~s}$ ) for the GC analysis.

The reaction progress was monitored using an Agilent 8890 GC system equipped with a 5977 B GC/MSD mass spectrometer (Waldbronn, BW, Germany) and a 122-7032 UI DB-Wax column (length: $30 \mathrm{~m}$, internal diameter: $0.250 \mathrm{~mm}$, and film thickness: $0.25 \mu \mathrm{m}$ ). Helium 6.0 was used as a carrier gas (column flow: $1.2 \mathrm{~mL} / \mathrm{min}$ ) with the following temperature program: Start at $35^{\circ} \mathrm{C}$ and hold for $4 \mathrm{~min}$, increase by $20 \mathrm{~K} / \mathrm{min}$ to $170{ }^{\circ} \mathrm{C}$ and hold for $4 \mathrm{~min}$.

\subsection{Surface Analysis}

TPR, TPD, and chemisorption measurements were performed on a TPDRO 1100 (Thermo Fisher Scientific, Waltham, MA, USA). Briefly, $80 \mathrm{mg}$ of the sample were placed in a quartz tube reactor, and temperature measurements were taken of the catalyst sample. The sample was pretreated at $250{ }^{\circ} \mathrm{C}$ for $60 \mathrm{~min}$ (heating rate: $20 \mathrm{~K} / \mathrm{min}$ ) and then reduced at $250{ }^{\circ} \mathrm{C}$ in $\mathrm{Ar} / \mathrm{H}_{2}\left(1.99 \%\right.$ vol. of $\mathrm{H}_{2}$, premixed, Linde Air Products $\left.\mathrm{GmbH}\right)$ at a flow rate of $30 \mathrm{~mL} / \mathrm{min}$ for $60 \mathrm{~min}$. For the desorption of the reversible adsorbed hydrogen, the sample was treated in a flow of argon $(30 \mathrm{~mL} / \mathrm{min})$ for $60 \mathrm{~min}$ and then cooled to $35^{\circ} \mathrm{C}$. $\mathrm{H}_{2}$ chemisorption was conducted at $35^{\circ} \mathrm{C}$ by pulsing pure hydrogen 15 times $(0.2094 \mathrm{~mL}$ per pulse) into a flow of $30 \mathrm{~mL} / \mathrm{min}$ of argon to saturate the metal surface with hydrogen. The adsorbed hydrogen was then determined through a comparison with the pulse signal height following saturation of the metal. For the calculation of the surface metal area, a stoichiometric factor $\mathrm{H}^{*}: \mathrm{M}_{\mathrm{s}}=1$ was assumed. The TOF was then calculated as follows:

$$
\mathrm{TOF}=\frac{\mathrm{n}(\mathrm{i}-\text { butanol })}{\mathrm{n}(\text { metal surface atoms }) * \mathrm{t}(\text { Reaction })} .
$$

Brunauer-Emmett-Teller (BET) measurements were then performed using a Quantachrome Autosorb iQ (version 5.20.17081, Düsseldorf, NRW, Germany). Degassing was performed at $150{ }^{\circ} \mathrm{C}(5 \mathrm{~K} / \mathrm{min})$ until dryness was achieved. Physisorption was then performed at $-196{ }^{\circ} \mathrm{C}$ in a liquid nitrogen bath. At least 18 points were measured in the range of $0.1-0.95 \mathrm{p} / \mathrm{p} 0$ for adsorption and desorption, respectively.

The SEM images were obtained using a Zeiss Gemini device (Oberkochen, BW, Germany) and EDX mapping was performed with an Oxford Ultimax detector. For the elemental composition determination, at least three spectra were taken of areas of at least $250 \mu \mathrm{m}$ in the $\mathrm{x}$ and $\mathrm{y}$ directions.

\subsection{ICP-OES Measurements}

Leaching of $\mathrm{Ru} / \mathrm{C}$ was measured with ICP-OES (Thermo Fisher Scientific, Waltham, MA, USA) on a calibrated instrument. Samples were prepared from $5 \mathrm{~mL}$ syringe-filtrated $\left(0.45 \mu \mathrm{m}\right.$ PTFE membrane, $\left.\mathrm{VWR}^{\mathrm{TM}}\right)$ reaction solution after $4 \mathrm{~h}$ reaction time. The solution was evaporated until dryness and treated with $1 \mathrm{~mL}$ of a 3:1 v/v mixture of $\mathrm{HCl}(37 \%$, p.A., Suprapur, Merck KGaA, Darmstadt, HE, Germany) and $\mathrm{HNO}_{3}(65 \%$, p.A., Suprapur, Merck KGaA, Darmstadt, HE, Germany). After heating the mixture to boiling, the clear solution was diluted with $1 \% \mathrm{HNO}_{3}$ to $20 \mathrm{~mL}$. For measurement, two parallel dilutions of the sample and the blind test containing only the used chemicals $(2000 \times$ and $1000 \times$ and $100 \times$ and $10 \times$ ) were prepared and analyzed.

\section{Conclusions}

The synthesis of i-butanol can best be performed with $\mathrm{Pt} / \mathrm{C}$ catalysts, with a slight decrease in activity over the reaction time. In this study, $\mathrm{Pt} / \mathrm{C}$ outperformed the other catalysts tested, whereas $\mathrm{Ru} / \mathrm{C}$ exhibited a reasonably high TOF for the synthesis of i-butanol, and also featured significant deactivation over the reaction time. Although $\mathrm{Cu} / \mathrm{C}$ featured the highest yields of acetaldehyde, the concentrations of i-butanol were extremely low. 
Reduction in the $\mathrm{Ir} / \mathrm{C}$ and $\mathrm{Cu} / \mathrm{C}$ catalysts negatively influenced activity regarding i-butanol synthesis and returned only very low yields. This was in accordance with the findings that ethanol and methanol dehydrogenation have a higher activation barrier on clean $\mathrm{Cu}$ surfaces.

When plotting the TOF of the transition metals of this study against their d-band centers, we identified a volcano curve whose maximum was at platinum. The same trend was observed in the literature with slight deviations. Plotting the TOF against the d-band center enabled us to explain the activity of $\mathrm{Ni} / \mathrm{C}, \mathrm{Pd} / \mathrm{C}$, and $\mathrm{Ru} / \mathrm{C}$ better than by correlation against the $\mathrm{H}$ adsorption energy.

We were able to conclusively show that the activity of the transition metals in the synthesis of i-butanol is well described when plotted against the d-band centers calculated by Hammer and Nørskov. This creates opportunities for rational catalyst development focused on the synthesis of carbon-neutral fuels. The insight into these relationships will help in synthesizing more active catalysts and exploiting the d-band engineering approach. As only the intrinsic d-band energy levels were offered by the different elements, it remains to be seen whether more favorable electronic properties can be achieved. In future experiments, d-band engineering will be performed with multi-metallic catalysts, aiming for an increased TOF and more stable catalyst activity. Increasing these catalyst characteristics will reduce the production costs of i-butanol synthesis and as well as the price gap to petroleum-based fuels, thus increasing customer acceptance.

Supplementary Materials: The following are available online at https://www.mdpi.com/2073 $-4344 / 11 / 3 / 406 / s 1$, Figure S1. Brunauer-Emmett-Teller (BET) isotherms for all tested catalysts. Adsorption and desorption branch. Figure S2. Barrett-Joyner-Halenda (BJH) pore size distributions of the used catalysts. Figure S3. Particle size distribution, established by scanning transmission electron microscopy (STEM).

Author Contributions: Conceptualization: J.H. and J.P.; methodology: J.H.; investigation: J.H., F.W., A.E., H.V., M.L.-C., and M.M.; writing — original draft preparation: J.H.; writing-review and editing: J.H., J.P., R.P.; A.E., H.V., M.L.-C., and M.M.; supervision: J.P. and R.P.; funding acquisition: R.P. and J.M. All authors have read and agreed to the published version of the manuscript.

Funding: This work was funded by the German Federal Ministry of Economic Affairs and Energy (BMWi), funding number: 19I18006P. Additionally, H.V. wishes to acknowledge the MEETHiEnD III-Materials and Components to Achieve High-Energy Density Batteries, funding number: 03XP0258C. M.M. would like to thank the Verbundvorhaben iNEW: Inkubator Nachhaltige Elektrochemische Wertschöpfungsketten, funding number: 03SF0589A.

Acknowledgments: J.H. wants to thank Detlef Stolten for supervision of the PhD thesis.

Conflicts of Interest: The authors have no conflict of interest to declare.

\section{References}

1. Biermann, M.; Gruß, H.; Hummel, W.; Gröger, H.C. Guerbet alcohols: From processes under harsh conditions to synthesis at room temperature under ambient pressure. ChemCatChem 2016, 8, 895-899. [CrossRef]

2. Gabriëls, D.; Hernández, W.Y.; Sels, B.; van der Voort, P.; Verberckmoes, A. Review of catalytic systems and thermodynamics for the Guerbet condensation reaction and challenges for biomass valorization. Catal. Sci. Technol. 2015, 5, 3876-3902. [CrossRef]

3. Wu, X.Y.; Fang, G.Q.; Tong, Y.Q.; Jiang, D.H.; Liang, Z.; Leng, W.H.; Liu, L.; Tu, P.X.; Wang, H.J.; Ni, J.; et al. Catalytic Upgrading of Ethanol to n-Butanol: Progress in Catalyst Development. ChemSusChem 2018, 11, 71-85. [CrossRef]

4. Pang, J.; Zheng, M.; Zhang, T. Synthesis of Ethanol and Its Catalytic Conversion; Elsevier: Amsterdam, The Netherlands, 2019; pp. 89-191, ISBN 9780128170991.

5. Ueda, W.; Yokoyama, T.; Moro-Oka, Y.; Ikawa, T. Enhancement of Surface Base Property of Magnesium Oxide by the Combination of Metal Ion. Chem. Lett. 1985, 14, 1059-1062. [CrossRef]

6. Cimino, S.; Lisi, L.; Romanucci, S. Catalysts for conversion of ethanol to butanol: Effect of acid-base and redox properties. Catal. Today 2018, 304, 58-63. [CrossRef]

7. Ndou, A.; Plint, N.; Coville, N.J. Dimerisation of ethanol to butanol over solid-base catalysts. Appl. Catal. A-Gen. 2003, 251, 337-345. [CrossRef]

8. Quesada, J.; Faba, L.; Diaz, E.; Ordonez, S. Copper-Basic Sites Synergic Effect on the Ethanol Dehydrogenation and Condensation Reactions. Chem CatChem 2018, 10, 3583-3592. [CrossRef] 
9. Zhang, J.; Shi, K.; An, Z.; Zhu, Y.; Shu, X.; Song, H.; Xiang, X.; He, J. Acid-Base Promoted Dehydrogenation Coupling of Ethanol on Supported Ag Particles. Ind. Eng. Chem. Res. 2020. [CrossRef]

10. Tsuchida, T.; Kubo, J.; Yoshioka, T.; Sakuma, S.; Takeguchi, T.; Ueda, W. Reaction of ethanol over hydroxyapatite affected by Ca/P ratio of catalyst. J. Catal. 2008, 259, 183-189. [CrossRef]

11. Ogo, S.; Onda, A.; Yanagisawa, K. Selective synthesis of 1-butanol from ethanol over strontium phosphate hydroxyapatite catalysts. Appl. Catal. A Gen. 2011, 402, 188-195. [CrossRef]

12. Riittonen, T.; Salmi, T.; Mikkola, J.P.; Wärnå, J. Direct Synthesis of 1-Butanol from Ethanol in a Plug Flow Reactor: Reactor and Reaction Kinetics Modeling. Top. Catal. 2014, 57, 1425-1429. [CrossRef]

13. Marcu, I.-C.; Tichit, D.; Fajula, F.; Tanchoux, N. Catalytic valorization of bioethanol over Cu-Mg-Al mixed oxide catalysts. Catal. Today 2009, 147, 231-238. [CrossRef]

14. Wu, X.Y.; Fang, G.Q.; Liang, Z.; Leng, W.H.; Xu, K.Y.; Jiang, D.H.; Ni, J.; Li, X.N. Catalytic upgrading of ethanol to n-butanol over $\mathrm{M}-\mathrm{CeO} 2 / \mathrm{AC}(\mathrm{M}=\mathrm{Cu}, \mathrm{Fe}, \mathrm{Co}, \mathrm{Ni}$ and Pd) catalysts. Catal. Commun. 2017, 100, 15-18. [CrossRef]

15. Furukawa, S.; Ehara, K.; Ozawa, K.; Komatsu, T. A study on the hydrogen activation properties of Ni-based intermetallics: A relationship between reactivity and the electronic state. Phys. Chem. Chem. Phys. 2014, 16, 19828-19831. [CrossRef] [PubMed]

16. Gorzkowski, M.T.; Lewera, A. Probing the Limits of d-Band Center Theory: Electronic and Electrocatalytic Properties of Pd-Shell-Pt-Core Nanoparticles. J. Phys. Chem. C 2015, 119, 18389-18395. [CrossRef]

17. Abe, H.; Yoshikawa, H.; Umezawa, N.; Xu, Y.; Saravanan, G.; Ramesh, G.V.; Tanabe, T.; Kodiyath, R.; Ueda, S.; Sekido, N.; et al. Correlation between the surface electronic structure and CO-oxidation activity of Pt alloys. Phys. Chem. Chem. Phys. 2015, 17, 4879-4887. [CrossRef]

18. Nilsson, A.; Pettersson, L.G.M.; Hammer, B.; Bligaard, T.; Christensen, C.H.; Nrskov, J.K. The electronic structure effect in heterogeneous catalysis. Catal Lett 2005, 100, 111-114. [CrossRef]

19. Hammer, B.; Norskov, J.K. Why gold is the noblest of all the metals. Nature 1995, 376, 238-240. [CrossRef]

20. Pettersson, L.G.M.; Nilsson, A. A Molecular Perspective on the d-Band Model: Synergy Between Experiment and Theory. Top. Catal. 2014, 57, 2-13. [CrossRef]

21. Abild-Pedersen, F.; Nilsson, A.; Nørskov, J.K. Comment on "Using Photoelectron Spectroscopy and Quantum Mechanics to Determine d-Band Energies of Metals for Catalytic Applications". J. Phys. Chem. C 2013, 117, 6914-6915. [CrossRef]

22. Hofmann, T.; Yu, T.H.; Folse, M.; Weinhardt, L.; Bär, M.; Zhang, Y.; Merinov, B.V.; Myers, D.J.; Goddard, W.A.; Heske, C. Using Photoelectron Spectroscopy and Quantum Mechanics to Determine d-Band Energies of Metals for Catalytic Applications. J. Phys. Chem. C 2012, 116, 24016-24026. [CrossRef]

23. Lu, C.; Lee, I.C.; Masel, R.I.; Wieckowski, A.; Rice, C. Correlations between the Heat of Adsorption and the Position of the Center of the D-Band: Differences between Computation and Experiment. J. Phys. Chem. A 2002, 106, 3084-3091. [CrossRef]

24. Siddiki, S.M.A.H.; Touchy, A.S.; Jamil, M.A.R.; Toyao, T.; Shimizu, K. C-Methylation of Alcohols, Ketones, and Indoles with Methanol Using Heterogeneous Platinum Catalysts. ACS Catal. 2018, 8, 3091-3103. [CrossRef]

25. Wouters, C.; Lehrheuer, B.; Heuser, B.; Pischinger, S. Ottomischkraftstoffe mit Methanol, Ethanol und Butanol. MTZ Mot. Z 2020, 81, 16-23. [CrossRef]

26. Schemme, S.; Breuer, J.L.; Samsun, R.C.; Peters, R.; Stolten, D. Promising catalytic synthesis pathways towards higher alcohols as suitable transport fuels based on $\mathrm{H} 2$ and $\mathrm{CO}_{2}$. J. CO2 Util. 2018, 27, 223-237. [CrossRef]

27. Singh, P.; Hui, X.; Sung, C.-J. Soot formation in non-premixed counterflow flames of butane and butanol isomers. Combust. Flame 2016, 164, 167-182. [CrossRef]

28. Hui, X.; Niemeyer, K.E.; Brady, K.B.; Sung, C.-J. Reduced Chemistry for Butanol Isomers at Engine-Relevant Conditions. Energy Fuels 2017, 31, 867-881. [CrossRef]

29. Brunauer, S.; Emmett, P.H.; Teller, E. Adsorption of Gases in Multimolecular Layers. J. Am. Chem. Soc. 1938, 60, 309-319. [CrossRef]

30. Neimark, A.V.; Sing, K.S.W.; Thommes, M. Surface Area and Porosity. In Handbook of Heterogeneous Catalysis, 2nd ed.; Wiley-VCH: Weinheim, Chichester, 2008; ISBN 3527312412.

31. Edington, J.W. Electron Diffraction in the Electron Microscope. In Electron Diffraction in the Electron Microscope; Edington, J.W., Ed.; Macmillan Education: London, UK, 1975; pp. 1-77. ISBN 978-0-333-18292-5.

32. Pasel, J.; Häusler, J.; Schmitt, D.; Valencia, H.; Meledina, M.; Mayer, J.; Peters, R. Ethanol Dehydrogenation: A Reaction Path Study by Means of Temporal Analysis of Products. Catalysts 2020, 10, 1151. [CrossRef]

33. Almithn, A.S.; Hibbitts, D.D. Supra-monolayer coverages on small metal clusters and their effects on $\mathrm{H} 2$ chemisorption particle size estimates. AIChE J. 2018, 64, 3109-3120. [CrossRef]

34. Héroguel, F.; Gebert, D.; Detwiler, M.D.; Zemlyanov, D.Y.; Baudouin, D.; Copéret, C. Dense and narrowly distributed silicasupported rhodium and iridium nanoparticles: Preparation via surface organometallic chemistry and chemisorption stoichiometry. J. Catal. 2014, 316, 260-269. [CrossRef]

35. Miller, J.T.; Meyers, B.L.; Modica, F.S.; Lane, G.S.; Vaarkamp, M.; Koningsberger, D.C. Hydrogen Temperature-Programmed Desorption (H2 TPD) of Supported Platinum Catalysts. J. Catal. 1993, 143, 395-408. [CrossRef]

36. Behm, R.J.; Penka, V.; Cattania, M.-G.; Christmann, K.; Ertl, G. Evidence for "subsurface" hydrogen on Pd(110): An intermediate between chemisorbed and dissolved species. J. Chem. Phys. 1983, 78, 7486-7490. [CrossRef] 
37. Montemore, M.M.; van Spronsen, M.A.; Madix, R.J.; Friend, C.M. O2 Activation by Metal Surfaces: Implications for Bonding and Reactivity on Heterogeneous Catalysts. Chem. Rev. 2018, 118, 2816-2862. [CrossRef]

38. Gervasini, A.; Bennici, S. Dispersion and surface states of copper catalysts by temperature-programmed-reduction of oxidized surfaces (s-TPR). Appl. Catal. A-Gen. 2005, 281, 199-205. [CrossRef]

39. Garbarino, G.; Riani, P.; Villa García, M.; Finocchio, E.; Sanchez Escribano, V.; Busca, G. A study of ethanol dehydrogenation to acetaldehyde over copper/zinc aluminate catalysts. Catal. Today 2020, 354, 167-175. [CrossRef]

40. Ponomareva, E.A. Copper Catalysts based on carbon-carbon fiburous materials for ethanol dehydrogenation. Russ. J. Appl. Chem. 2016, 89, 598-602. [CrossRef]

41. Ponomareva, E.A. Dehydrogenation of ethanol over carbon-supported Cu-Co catalysts modified by catalytic chemical vapor deposition. React. Kinet. Mech. Catal. 2017, 122, 399-408. [CrossRef]

42. Wang, Q.-N.; Shi, L.; Li, W.; Li, W.-C.; Si, R.; Schüth, F.; Lu, A.-H. Cu supported on thin carbon layer-coated porous SiO 2 for efficient ethanol dehydrogenation. Catal. Sci. Technol. 2018, 8, 472-479. [CrossRef]

43. Zhang, P.; Wang, Q.-N.; Yang, X.; Wang, D.; Li, W.-C.; Zheng, Y.; Chen, M.; Lu, A.-H. A Highly Porous Carbon Support Rich in Graphitic-N Stabilizes Copper Nanocatalysts for Efficient Ethanol Dehydrogenation. ChemCatChem 2017, 9, 505-510. [CrossRef]

44. Li, M.-Y.; Lu, W.-D.; He, L.; Schüth, F.; Lu, A.-H. Tailoring the Surface Structure of Silicon Carbide Support for Copper Catalyzed Ethanol Dehydrogenation. ChemCatChem 2019, 11, 481-487. [CrossRef]

45. Hammer, B.; Nørskov, J.K. Theoretical surface science and catalysis—calculations and concepts. In Impact of Surface Science on Catalysis; Gates, B.C., Ed.; Academic Press: San Diego, CA, USA, 2000; pp. 71-129. ISBN 9780120078455.

46. Li, M.; Borsay, A.; Dakhchoune, M.; Zhao, K.; Luo, W.; Züttel, A. Thermal stability of size-selected copper nanoparticles: Effect of size, support and $\mathrm{CO}_{2}$ hydrogenation atmosphere. Appl. Surf. Sci. 2020, 510, 145439. [CrossRef]

47. Bowker, M.; Madix, R.J. XPS, UPS and thermal desorption studies of alcohol adsorption on Cu(110). Surf. Sci. 1982, 116, 549-572. [CrossRef]

48. WACHS, I. The selective oxidation of $\mathrm{CH}_{3} \mathrm{OH}$ to $\mathrm{H}_{2} \mathrm{CO}$ on a copper(110) catalyst. J. Catal. 1978, 53, 208-227. [CrossRef]

49. Shan, J.; Lucci, F.R.; Liu, J.; El-Soda, M.; Marcinkowski, M.D.; Allard, L.F.; Sykes, E.C.H.; Flytzani-Stephanopoulos, M. Water co-catalyzed selective dehydrogenation of methanol to formaldehyde and hydrogen. Surf. Sci. 2016, 650, 121-129. [CrossRef]

50. Boucher, M.B.; Marcinkowski, M.D.; Liriano, M.L.; Murphy, C.J.; Lewis, E.A.; Jewell, A.D.; Mattera, M.F.G.; Kyriakou, G.; FlytzaniStephanopoulos, M.; Sykes, E.C.H. Molecular-scale perspective of water-catalyzed methanol dehydrogenation to formaldehyde. ACS Nano 2013, 7, 6181-6187. [CrossRef]

51. Wanke, S.E.; Flynn, P.C. The Sintering of Supported Metal Catalysts. Catal. Rev. 1975, 12, 93-135. [CrossRef]

52. Gao, P.; Wang, A.; Wang, X.; Zhang, T. Synthesis of Highly Ordered Ir-Containing Mesoporous Carbon Materials by OrganicOrganic Self-Assembly. Chem. Mater. 2008, 20, 1881-1888. [CrossRef]

53. Liu, Q.; Xu, G.Q.; Wang, Z.D.; Liu, X.R.; Wang, X.C.; Dong, L.L.; Mu, X.D.; Liu, H.Z. Iridium Clusters Encapsulated in Carbon Nanospheres as Nanocatalysts for Methylation of (Bio)Alcohols. ChemSusChem 2017, 10, 4748-4755. [CrossRef] [PubMed]

54. Hoffmann, R. Solids and Surfaces: A Chemist's View of Bonding in Extended Structures; Print on demand der Ausg, 1988; Wiley-VCH: New York, NY, USA, 2002; ISBN 0471187100.

55. Kovács, A.; Schierholz, R.; Tillmann, K. FEI Titan G2 80-200 CREWLEY. JLSRF 2016, 2. [CrossRef] 